\title{
CARDIOPULMONARY BYPASS REDUCES PULMONARY SURFACTANT ACTIVITY IN INFANTS
}

M. Griese, MD

C. Wilnhammer, MD

S. Jansen*

C. Rinker, MD
Objective: Infants younger than 1 year of age undergoing cardiopulmonary bypass surgery often have severe lung injury necessitating increased postoperative respiratory mechanical support. Inasmuch as the mechanisms may involve an impairment of the pulmonary surfactant system, our aim was to determine whether changes of surfactant occur in such infants. Methods: From the day of the operation to day 7 after the operation, serial tracheobronchial small-volume lavages of 19 infants (aged $166 \pm 29$ days) were fractionated into a small and a large surfactant aggregate fraction and compared with those of 13 infants without lung disease (aged $203 \pm 33$ days). Results: After cardiac operations with cardiopulmonary bypass surgery, total protein in lavages was increased 3-fold to 4-fold and decreased linearly with time. Surfactant protein $A$ was increased on day 1 and day 2 and then decreased, whereas surfactant protein $B$ and total phospholipids were increased on day 1. The ratio of phospholipids in small and large surfactant fractions was unchanged, but the surface activity of the large-aggregate surfactant was impaired on days 1 to 3 . Conclusions: Lung injury in infants after cardiopulmonary bypass surgery involves significant biochemical and functional disturbances of the pulmonary surfactant system. Inasmuch as substitution with natural surfactant might correct these deficiencies, the potential of this approach to reduce postoperative morbidity needs to be investigated. (J Thorac Cardiovasc Surg 1999;118:237-44)
C ardiopulmonary bypass (CPB) surgery induces an acute lung injury. ${ }^{1}$ Because the severity of the injury is proportional to the duration of $\mathrm{CPB}$, infants less than 1 year of age who often have complex cardiac anomalies represent a group at a higher risk. ${ }^{2}$ The lung injury is mainly initiated by shear forces and from contact of venous blood with the nonphysiologic surfaces of the CPB circuit, resulting in activated platelets that release mediators and in activation of the complement and the kallikrein-kinin systems. ${ }^{3-5}$ Very early on, polymorphonuclear granulocytes are activated, and up to $50 \%$ of the peripheral leukocytes may be sequestered into the

From Kinderklinik and Kinderpoliklinik im Dr von Haunerschen Kinderspital, Ludwig-Maximilians-University, Munich, Germany. Received for publication Sept 22, 1998; revisions requested March 4, 1999; revisions received April 1, 1999; accepted for publication April 2, 1999.

Address for reprints: Matthias Griese, MD, The Lung Research Group, Kinderklinik and Kinderpoliklinik im Dr von Haunerschen Kinderspital, Ludwig-Maximilians-University, Pettenkoferstr 8a, D-80336 Munich, Germany.

*This article contains parts of the medical thesis of S. Jansen.

Copyright (C) 1999 by Mosby, Inc.

$0022-5223 / 99 \$ 8.00+0 \quad \mathbf{1 2 / 1 / 9 9 0 9 8}$ lung vascular system. This may be particularly detrimental in infants because of their higher capillary surface per unit of lung volume. ${ }^{6,7}$ Damage to the lung capillary endothelium results in interstitial edema, and damage to the alveolar epithelial cells results in alveolar flooding and edema. ${ }^{5}$

The edema fluid might directly inactivate the surfaceactive properties of pulmonary surfactant, which are of critical importance to keep the terminal air spaces patent during respiration and to prevent alveoli from filling with fluid. ${ }^{8,9}$ Normal intra-alveolar surfactant metabolism with conversion of the surface-active largeaggregate forms into small aggregates may also become abnormal. ${ }^{10}$ Last, with precipitating lung injury, damage to the alveolar type II epithelial cells results in alterations of surfactant synthesis, secretion, and composition. ${ }^{10}$ All these secondary surfactant abnormalities have been described in acute respiratory distress syndrome of various causes. The functional relevance of surfactant abnormalities in acute respiratory distress syndrome is suggested by successful treatment with exogenous natural surfactant. ${ }^{10-13}$

Thus the goal of this study was to better define potential indications for surfactant therapy in a group of 
Table I. Clinical characteristics of the patients

\begin{tabular}{llcc}
\hline $\begin{array}{l}\text { Patient } \\
\text { age [d], sex })\end{array}$ & \multicolumn{1}{c}{ Diagnosis } & $\begin{array}{c}\text { Total time } \\
\text { on bypass } \\
(\text { min })\end{array}$ & $\begin{array}{c}\text { Removal of } \\
\text { endotracheal } \\
\text { tube }(d)\end{array}$ \\
\hline $1(300, \mathrm{~F})$ & TOF & 214 & 14 \\
$2(17, \mathrm{~F})$ & ASD & 132 & 9 \\
$3(34, \mathrm{~F})$ & TAPVC & 94 & 3 \\
$4(6, \mathrm{M})$ & Ivemark syndrome & 139 & $1 \dagger$ \\
& $\quad$ with complex & & \\
$5(152, \mathrm{M})$ & cardiac anomaly & & \\
$6(362, \mathrm{M})$ & CAVSD & 132 & 3 \\
$7(184, \mathrm{M})$ & CAVSD & 138 & 7 \\
$8(328, \mathrm{~F})$ & CAVSD & 149 & 4 \\
$9(298, \mathrm{M})$ & VSD & 204 & 23 \\
$10(232, \mathrm{M})$ & VSD & 73 & 1 \\
$11(189, \mathrm{~F})$ & VSD, ASD & 68 & 1 \\
$12(184, \mathrm{M})$ & VSD, ASD & 90 & 3 \\
$13(141, \mathrm{~F})$ & VSD & 140 & 3 \\
$14(13, \mathrm{~F})$ & TAC, ASD & 246 & 16 \\
$15(168, \mathrm{~F})$ & TAC & 172 & $19+$ \\
$16(148, \mathrm{M})$ & TGA, LVOTO, VSD & 221 & 7 \\
$17(26, \mathrm{M})$ & TGA, PDA, VSD, & 225 & 14 \\
& ASD & & \\
$18(2, \mathrm{~F})$ & TGA, PDA, ASD & 228 & 17 \\
$19(378, \mathrm{M})$ & DIRV & 113 & 5 \\
\hline & & &
\end{tabular}

Patients 8 and 14 had a severe nosocomial infection and were not included in the final analysis of the surfactant status. ASD, Atrial septal defect; CAVSD, complete atrioventricular septal defect; DIRV, double-inlet right ventricle; LVOTO, left ventricular outflow tract obstruction; VSD, ventricular septal defect; $P D A$, persistent ductus arteriosus; $T A C$, truncus arteriosus communis; $T A P V R$, total anomalous pulmonary venous return; $T G A$, transposition of the great arteries; TOF, tetralogy of Fallot.

$†$ Died.

$\$$ Transferred to another hospital receiving ventilatory support.

infants who were at risk for severe lung injury after $\mathrm{CPB}$. We have characterized the biochemical and functional state of their pulmonary surfactant, obtained from serial small-volume lavages.

\section{Patients and methods}

Control infants. We studied 13 infants ( 8 male) healthy with respect to cardiopulmonary disease (aged $203 \pm 33$ days, range 8-391 days). None had a history of chronic respiratory symptoms or recent upper or lower respiratory tract infections. All these infants were undergoing elective nuclear magnetic resonance imaging for diagnosis of conditions such as hydrocephalus $(\mathrm{n}=5)$, hepatoblastoma $(\mathrm{n}=2)$, ocular abnormalities $(n=2)$, battered child syndrome $(n=1)$, neuroblastoma $(\mathrm{n}=1)$, developmental retardation $(\mathrm{n}=1)$, and spinal abnormalities $(\mathrm{n}=1)$. Small-volume lavage was performed by the blind suctioning technique described below in detail during general anesthesia $\left(\mathrm{N}_{2} \mathrm{O}\right.$, oxygen, halothane $1 \%$ $5 \%$ ) and tracheal intubation. The study was approved by our institutional review board and informed consent was obtained from the parents before the study.

Infants with CPB. Small-volume lavages from 19 consec- utive infants with congenital heart disease who underwent cardiac operations with CPB at the Department of Cardiac Surgery, Klinikum Grosshadern, University of Munich, were prospectively collected. Mean age of the infants at operation was $166 \pm 29$ days (range 2-378 days) and details of the infants are given in Table I. For CPB the bypass circuit was primed with $500 \mathrm{~mL}$ of red blood cells and balanced electrolyte solution. After administration of heparin (activated clotting time about 500 seconds), the right atrium-to-aorta $\mathrm{CPB}$ was initiated. The patients were cooled to $28^{\circ} \mathrm{C}-18^{\circ} \mathrm{C}$ during $\mathrm{CPB}$ and the lungs were not ventilated. After rewarming, ventilation was recommenced with an inspired oxygen fraction $\left(\mathrm{FIO}_{2}\right)$ of 1.0 and circulation was reestablished. Once in clinically stable condition, the infants were transferred to the intensive care unit, and intermittent positive-pressure ventilation was continued. The oxygenation index (OI) was calculated as follows: $\mathrm{OI}=$ (Mean airway pressure $\times$ Arterial $\left.\mathrm{PO}_{2}\right) / \mathrm{FIO}_{2}$. Mean airway pressure was derived from this formula: (Ventilatory rate $\times$ Inspiratory time/60) $\times[($ Peak inspiratory pressure - Positive end-expiratory pressure) + Positive end-expiratory pressure], as used earlier. ${ }^{14}$ The study was approved by our institutional review board and informed consent from the parents was obtained before the study.

Small-volume lavage procedure and preparation of lavage fractions. For small-volume lavage, an open-ended suctioning catheter was inserted blindly through the endotracheal tube and wedged in a distal airway. Then $0.9 \%$ saline solution was instilled at an amount of $1 \mathrm{~mL} / \mathrm{kg}$ body weight and withdrawn by gentle suctioning. After filtration through gauze and centrifugation at $200 \mathrm{~g}$ for 10 minutes to remove the cells and debris, the supernatant was stored at $-70^{\circ} \mathrm{C}$. The cell-free supernatant was fractionated by differential centrifugation at $40,000 \mathrm{~g}, 4^{\circ} \mathrm{C}$ for 30 minutes, into a fraction that contained the small surfactant aggregates, which have less surface activity, and the more surface-active fraction containing the large surfactant aggregates. ${ }^{15-17}$

Phospholipid analysis. As described before, ${ }^{17}$ aliquots of the samples were lipid extracted and the phospholipid content was determined from the content of inorganic phosphate. After separation of phospholipids by high-performance thinlayer chromatography, the distribution of phospholipid classes was assessed from the phosphorus content of the individual spots, which were identified by authentic standards. Phospholipid data are expressed as milligrams of phosphate measured. Inasmuch as $4 \%$ of the phospholipid mass is phosphate, the amount of phospholipids in milligrams can be calculated by being multiplied by 25 . All measurements were done in duplicate.

ELISA (solid-phase enzyme-linked immunosorbent assay) for surfactant protein $A$ and surfactant protein $B$. These assays were performed as described previously in detail. ${ }^{18}$ The samples were assessed in duplicate.

Surface tension. The surface tension modifying properties of the specimens were evaluated in a pulsating bubble surfactometer (Electronetics, Amherst, NY). Before measurement, the samples were resuspended at a phospholipid concentration of $1 \mathrm{mg} / \mathrm{mL}$ in $140 \mathrm{mmol} / \mathrm{L} \mathrm{NaCl}, 10 \mathrm{mmol} / \mathrm{L}$ HEPES, $0.5 \mathrm{mmol} / \mathrm{L}$ ethylenediaminetetraacetic acid, and $3 \mathrm{mmol} / \mathrm{L}$ 


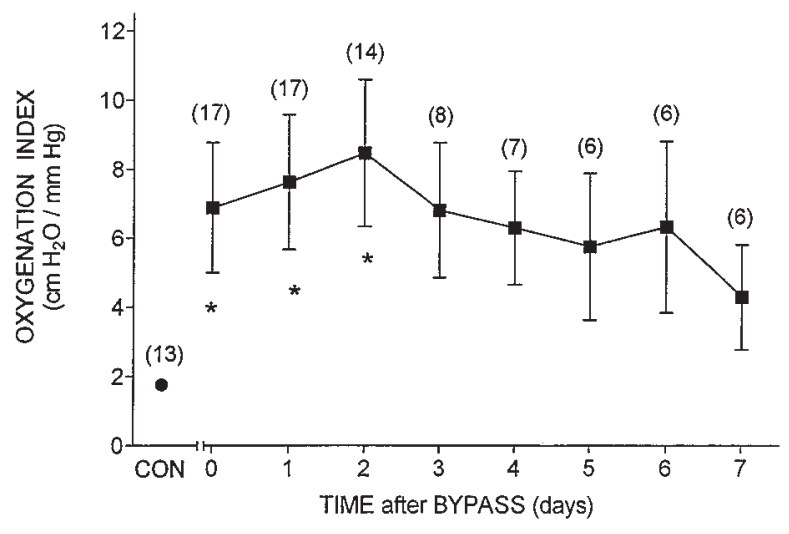

Fig 1. Time course of the oxygenation index of the infants treated with CPB. For comparison, values from a control group of infants without lung disease are given. The data from infants 8 and 14, who had a nosocomial infection, were not included. Data are means \pm SEM of $\mathrm{n}$ different subjects at each time point. *Indicates a difference from the control group (on day $0, P=.043$; day $1, P=.023$; day $2, P=.009$; and day $3, P=.021)$.

$\mathrm{CaCl}_{2}, \mathrm{pH} 6.9$, at $37^{\circ} \mathrm{C}$. Adsorption $\left(\gamma_{\text {ads }}\right)$ was defined as the surface tension obtained 10 seconds after formation of the bubble. Minimum surface tension $\left(\gamma_{\text {min }}\right)$ was the surface tension in the equilibrium after 3 minutes of pulsations (20 cycles/min; minimum $0.40 \mathrm{~mm}$ and maximum $0.55 \mathrm{~mm}$ radius), read at a minimum radius of the bubble by an automated computer program. ${ }^{18}$

Inhibition of surfactant function. To determine the inhibitory potential of surfactant-associated lavage constituents, the water-soluble components of the large-aggregate fraction obtained during the lipid extraction procedure was tested for its effectiveness in inhibiting a functionally active surfactant. ${ }^{18}$ In brief, the watery upper phase of the lipid extraction was collected, its protein content was determined (Biorad, Munich, Germany), and it was then lyophilized in a centrifuge under reduced pressure (Vacuum concentrator, Bachhofen, Munich, Germany). The lyophilized proteins were reconstituted in bubble buffer in such a way that the final protein concentration was $2 \mathrm{mg} / \mathrm{mL}$ after being mixed with a natural bovine surfactant (phospholipid concentration of $0.25 / \mathrm{mL}$ ). For purposes of comparison, the natural surfactant was also analyzed in the absence of protein and with serum at various concentrations. The mixtures were spun in a vortex and measured in the bubble surfactometer as described earlier.

Statistical analysis. With time after CPB and clinical recovery, the number of infants remaining intubated steadily decreased. In addition, sufficient sample was not available from all infants at all time points, and we set priorities regarding which variables should be investigated first. We first determined the phospholipid content and the surface activity of a sample. Because of the relatively low content of phospholipids, especially in the small-aggregate fraction, this fraction
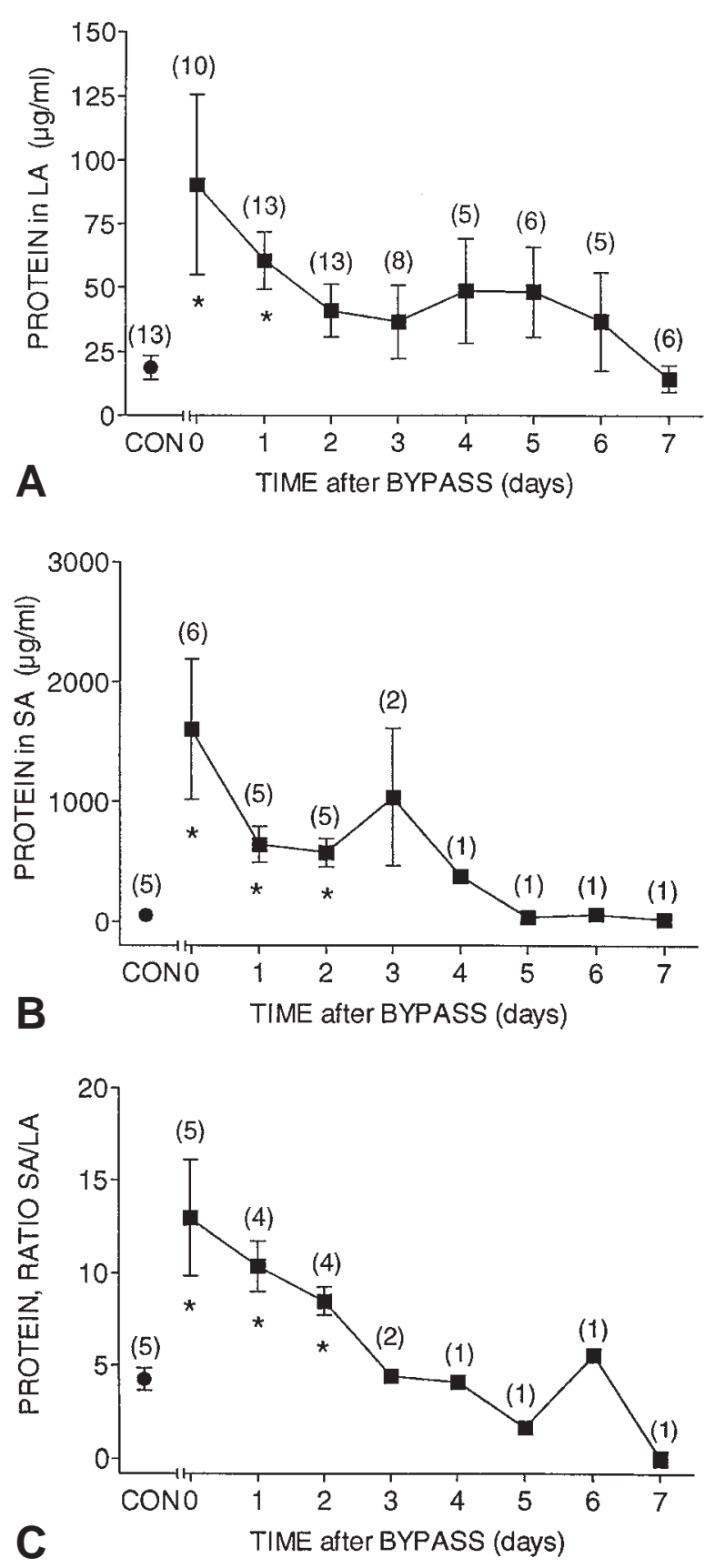

Fig 2. Total protein in the large-aggregate fraction $(L A)(\mathbf{A})$ and small-aggregate fraction $(S A)(\mathbf{B})$ of the lavage. C, Ratio of protein in small- and large-aggregate $(S A / L A)$ fractions. Comparisons with the control group were made by $t$ test. A, On day $0, P=.028$; day $1, P=.002$. B, On day $0, P=.033$; day $1, P=.004$; day $2, P=.001$. $\mathbf{C}$, On day $0, P=.032$; day $1, P=.004$; day $2, P=.008$. Data are means \pm SEM of $\mathrm{n}$ different subjects at each time point.

was sometimes used up completely, even without obtaining sufficient material for analysis. The number of independent data points from different individuals, determined in dupli- 

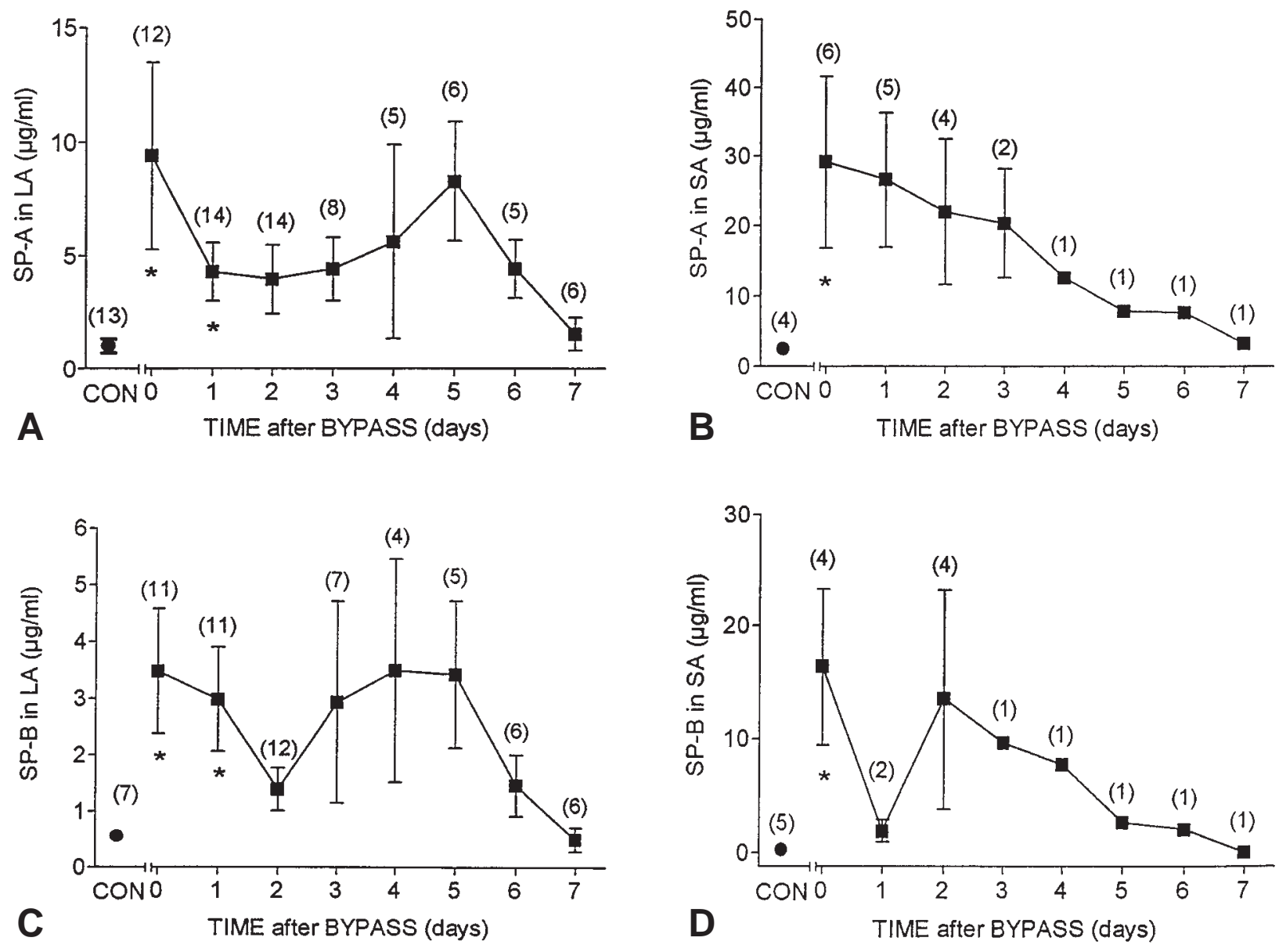

Fig 3. Surfactant protein A $(S P-A)(\mathbf{A}$ and $\mathbf{B})$ and surfactant protein $\mathrm{B}(S P-B)(\mathbf{C}$ and $\mathbf{D})$ in the large-aggregate fraction (LA) (upper panels) and small-aggregate fraction $(S A)$ (lower panels) of the lavage. Comparisons with the control group were made by $t$ test. $\mathbf{A}$, On day $0, P=.045$; day $1, P=.024$. B, On day $0, P=.045$; $\mathbf{C}$, On day 0 , $P=.045$; day $1, P=.024$. D, On day $0, P=.028$. Data are means \pm SEM of $\mathrm{n}$ different subjects at each time point.

cate, are therefore indicated in the figures at each time point and for each variable separately. All data are means \pm standard error of the mean (SE) for $\mathrm{n}$ independent determinations. To calculate the standard deviation of the data, multiply SE by $\sqrt{ } \mathrm{n} .{ }^{19}$ Spearman rank correlation coefficients were calculated at each time interval and also for pooled data to estimate correlations between oxygenation index, surface activity, and the biochemical variables. Comparisons were made by the $t$ test. Exact $P$ values are given where indicated. In all other cases, $P$ was > 0.1. Graph Pad Prism software (San Diego, Calif) was used for data analysis. ${ }^{19}$

\section{Results}

For the first few days after the operation the oxygenation index was elevated above the level of the control infants (Fig 1). In 2 infants (infants 8 and 14, Table I) the respiratory support necessary increased with time, their clinical status deteriorated, and the markers of inflammation increased. Both infants responded to a change in the antibiotic regimen, but only in 1 was an infectious agent identified (positive blood culture on day 3 with Enterobacter cloacae). These infants with suspected nosocomial infection were excluded from the analyses presented. In all the other infants the prolonged intubation was due to pulmonary dysfunction and was not related to hemodynamic problems, infections, or other issues. This clear clinical impression is supported by the data that the time to removal of the endotracheal tube increased in proportion with the duration of $\mathrm{CPB}$ $(P=.0005, r=0.717)$ (Table I). A longer CPB period had resulted in more severe lung injury.

Total protein in lavages immediately after $\mathrm{CPB}$ was increased 4 to 20 times above the levels of the control infants (protein in large surfactant aggregate, 18.6 \pm 4.7 $\mu \mathrm{g} / \mathrm{mL}$; in small surfactant aggregates, $52.9 \pm 20.8$ 
Table II. Phospholipid composition of the largeaggregate fraction of small-volume lavages from control infants and from infants 1 day after $C P B$

\begin{tabular}{lrcc}
\hline $\begin{array}{l}\text { Phospholipid class } \\
\text { (\% of total phospholipids) }\end{array}$ & $\begin{array}{c}\text { Control } \\
\text { infants } \\
(n=8)\end{array}$ & $\begin{array}{c}\text { Infants 1 day } \\
\text { after } C P B \\
(n=5)\end{array}$ & P value \\
\hline Lysophosphatidylcholine & $0.2 \pm 0.1$ & $0.6 \pm 0.2$ & .123 \\
Sphingomyelin & $0.8 \pm 0.5$ & $1.5 \pm 0.2$ & .246 \\
Phosphatidylcholine & $79.7 \pm 1.4$ & $72.4 \pm 1.1$ & .004 \\
Phosphatidylinositol & $4.8 \pm 0.7$ & $6.1 \pm 1.2$ & .362 \\
Phosphatidyserine & $1.8 \pm 0.3$ & $2.9 \pm 0.2$ & .043 \\
Phosphatidylethanolamine & $2.7 \pm 0.7$ & $5.3 \pm 0.8$ & .035 \\
Phosphatidylglycerol & $10.0 \pm 3.1$ & $7.7 \pm 1.3$ & .592 \\
Phosphatidic acid & $2.1 \pm 0.5$ & $2.3 \pm 0.4$ & .756 \\
Cardiolipin & $0.8 \pm 0.3$ & $0.5 \pm 0.1$ & .539 \\
\hline
\end{tabular}

Mean \pm SEM, unpaired, 2-sided $t$ test.

$\mu \mathrm{g} / \mathrm{mL}$ ) (Fig 2, $A$ and $B$ ). The increase was pronounced particularly in the small-aggregate fraction (Fig 2, C). The surfactant associated proteins A and B followed a similar course: on day 0 or day 1 , they were increased several times above the levels of the controls (surfactant protein A in large surfactant aggregates, $1.0 \pm 0.3$ $\mu \mathrm{g} / \mathrm{mL}$, and in small surfactant aggregates, $2.5 \pm 0.2$ $\mu \mathrm{g} / \mathrm{mL}$; surfactant protein B in large surfactant aggregates, $0.6 \pm 0.1 \mu \mathrm{g} / \mathrm{mL}$, and in small surfactant aggregates, $0.3 \pm 0.06 \mu \mathrm{g} / \mathrm{mL}$ ) (Fig 3). As mentioned in the "Methods" section, especially for these two variables in the small-aggregate fraction, only a limited number of samples was available.

The phospholipid content of the large-aggregate fraction was about 4 times greater than that of the smallaggregate fraction. Only on the day of CPB was a significantly increased phospholipid content above the level of the control infants observed (phospholipids [expressed as micrograms of phosphate] in large surfactant aggregates, $12.5 \pm 6.4 \mu \mathrm{g} / \mathrm{mL}$, and in small surfactant aggregates, $1.4 \pm 0.4 \mu \mathrm{g} / \mathrm{mL}$ ) (Fig 4, $A$ and $B$ ). In contrast to total protein, the ratio of small to large surfactant aggregates was not altered (Fig 4, C). On day 1 after CPB the phospholipid composition of the largeaggregate fraction was still very characteristic for pulmonary surfactant and differed only slightly from that of the control infants (Table II).

Minimal surface tension, as a measure of the surface activity, of the native large-aggregate fraction was higher than in control infants from day 1 to day 3 (Fig $5, A$ ). This was not the case with the lipid extract (Fig $5, B)$. These data suggested an inhibitory role of the proteinaceous water-soluble fraction of native large surfactant aggregates after CPB. Indeed, such an activity was demonstrated (Fig 6). However, on an equal
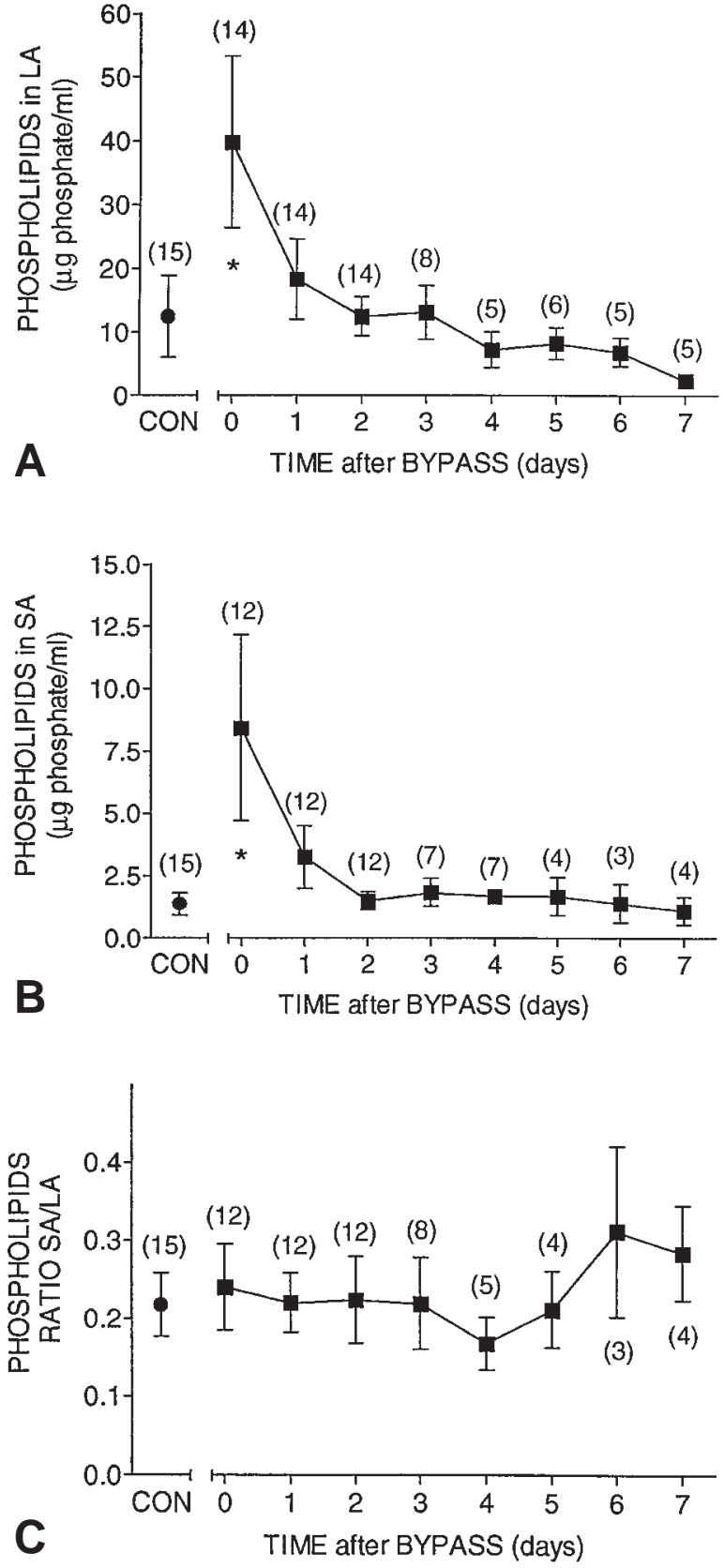

Fig 4. Phospholipids in the large-aggregate fraction $(L A)$ (A) and small-aggregate fraction $(S A)(\mathbf{B})$ of the lavage. C, Ratio of phospholipids in small- and large-aggregate $(S A / L A)$ fractions. Comparisons with the control group were made by $t$ test. $\mathbf{A}$, On day $0, P=.048$. $\mathbf{B}$, On day $0, P=.035$. Data are means \pm SEM of $n$ different subjects at each time point.

weight basis, we did not find any difference between the effect of the proteinaceous fraction isolated from control infants and that from infants after CPB. Thus there was no evidence for specific and more potent 

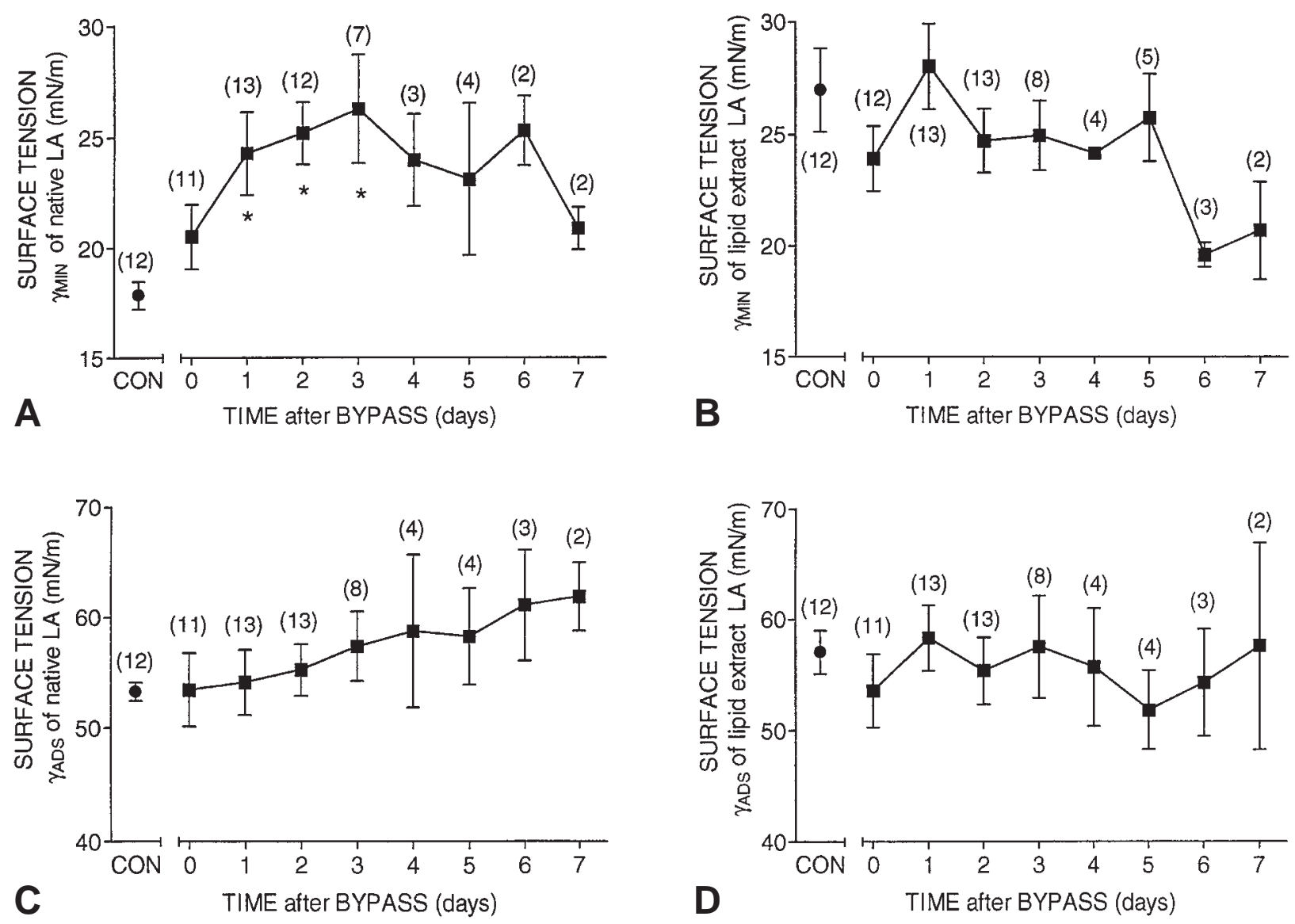

Fig 5. Surface tension of the large-aggregate fraction $(L A)$ in the native state $(\mathbf{A}$ and $\mathbf{C})$ and of its lipid extract $(\mathbf{B}$ and D). Minimal surface tension of the pulsating bubble $\left(\gamma_{\min }\right)(\mathbf{A}$ and $\mathbf{B})$ and of the static bubble after adsorption $\left(\gamma_{\mathrm{ads}}\right)(\mathbf{C}$ and $\mathbf{D})$. *Indicates a difference from the control group, assessed by $t$ test. A, On day $1, P=.005$; day 2, $P=.001$; day 3, $P=.001$. Data are means \pm SEM of $\mathrm{n}$ different subjects at each time point.

inhibitors present in the CPB sample only (Fig 6). Even so, the total protein concentration has to be considered in the infants with CPB that was increased several-fold above control levels on the first few postoperative days. No differences in the rate of adsorption between control infants and infants after CPB were observed (Fig 5, $B$ and $D$ ). Multiple regression analysis among the variables investigated (oxygenation index, protein, phospholipids, surfactant proteins $\mathrm{A}$ and $\mathrm{B}, \gamma_{\min }$ ) did not reveal significant correlations.

\section{Discussion}

The presence of severe biochemical and functional abnormalities of pulmonary surfactant and the recent success of exogenous natural surfactant substitution suggest an important role of impaired surfactant in acute lung injury and acute respiratory distress syndrome. ${ }^{10-13}$ However, little is known about surfactant after $\mathrm{CPB}$, especially in young infants in whom acute lung injury is more likely to develop. In this setting of a rather homogeneous population and with infants of a relatively low body weight, the administration of sufficient amounts (eg, 200-500 mg/kg body weight) of surfactant appears feasible. However, to our knowledge no data on the pulmonary surfactant activity are as yet available in this group of infants.

In our serial analysis of the small-volume lavages, we found reduced surface activity of the large-aggregate surfactant fraction from postoperative day 1 to day 3 . This was concurrent with an increase of the oxygenation index, although no correlations between these two variables were found in the individual data sets. Previously, it was shown that surfactant extracted from lungs of patients after $\mathrm{CPB}$ at autopsy also had a reduced capacity to lower surface tension in vitro. ${ }^{20}$ Others have demonstrated biochemical abnormalities 
of surfactant, for example, quantitative alterations of individual phospholipid species 24 hours and 8 days after CPB in adults. ${ }^{21}$ In older children the ratio of phosphatidylcholine in small and large surfactant aggregates was found to be increased 1 hour after CPB. ${ }^{22}$

Several lines of evidence support the view that the impaired surface activity observed was mainly due to the inhibition of surfactant function by edema fluid, and not due to compositional deficiencies. First, the surface activity of the lipid-extracted large surfactant aggregate, for example, after removal of the nonlipid components, was the same in controls and in infants after $\mathrm{CPB}$, and there were no differences after $\mathrm{CPB}$ (Fig 5, B). Second, the proteins isolated from the largeaggregate fraction were strongly inhibitory (Fig 6), and they were increased several-fold on the first few days after CPB (Fig 2). The concomitant increases in surfactant proteins A and B and phospholipids (Figs 3 and 4) are likely to have compensated a more severe deterioration of surface activity of the native large-aggregate fraction. Last, the phospholipid composition of the surfactant isolated from day 1 after CPB was characteristic of normal surfactant ${ }^{18}$ and appeared not sufficiently different from that of control infants to explain such differences in surface activity (Table II). On the other hand, we cannot completely rule out the possibility of other functional alterations of the surfactant components, for example, from proteolytic alterations of the surfactant-specific proteins, that might not be detectable in our ELISA-type assays.

The general increase of surfactant components (eg, total phospholipids and surfactant proteins A and B) we found on the day of CPB may be due to a massive secretory release of surfactant from intracellular stores after reexpansion of the lungs after CPB that was not counterbalanced by re-uptake..$^{23,24}$ Although this notion is supported by the minor changes of the phospholipid pattern on day 1 after CPB and by a constant ratio of phospholipids in small and large surfactant aggregates, it remains speculative unless surfactant fluxes are measured in these infants.

A limitation of our study results from the inability to obtain adequate samples on all patients owing to the small sample size and low lavage volume. This resulted in relatively incomplete data on the proteins in the small-aggregate fraction. Additionally, the fact that the patients gradually dropped out of the study as they became extubated may have biased the data, especially at later time points. Because of this and because no longitudinal data analysis was performed, no conclusions related to the pattern of changes across time can be made. Thus mainly data from the first few postopera-

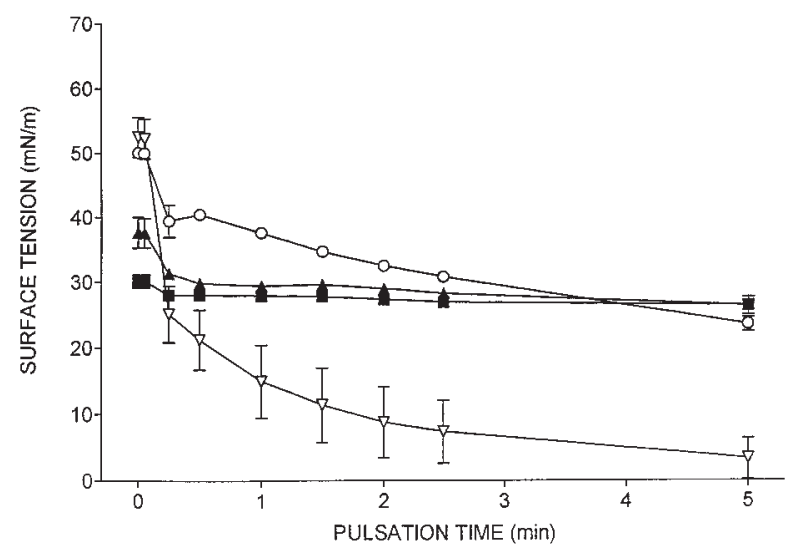

Fig 6. Inhibition of surfactant function by lavage constituents and serum. A natural bovine surfactant (phospholipid concentration $0.25 \mathrm{mg} / \mathrm{mL}$ ) was mixed with the proteinaceous extract isolated from the large-aggregate fraction $(L A)$ of the lavages of the control infants (filled triangles, $\mathrm{n}=4$ ) and of infants 2 to 4 days after CPB (filled squares, $\mathrm{n}=11$ ) at a protein concentration of $4 \mathrm{mg} / \mathrm{mL}$. There were no differences between the 2 groups. For comparison, surfactant alone reduced surface tension to low values (open triangles, $\mathrm{n}=7$ ). In the presence of normal human serum (protein concentration $4 \mathrm{mg} / \mathrm{mL}$ ), the surface activity of the natural bovine surfactant was similarly inhibited as in the presence of the material isolated from the lavages (open circles, $\mathrm{n}=7$ ).

tive days can safely be compared with those of the control infants.

Our study was performed in relatively sick infants undergoing $\mathrm{CPB}$ of much longer duration than in earlier studies and thus having a substantial risk of postoperative severe lung injury. This was associated with significant functional disturbances of the pulmonary surfactant activity, indicating a possible role for surfactant therapy. The surfactant preparation to be used should have a high resistance to inhibition by proteinaceous edema fluid. ${ }^{8,25}$ Thus only preparations containing the surfactant proteins or their analogs are likely to be successful. This is in line with previous experience in adult patients, in whom the administration of a relatively small dose (about $45 \mathrm{mg} / \mathrm{kg}$ body weight) of a pure phospholipid mixture, did not improve lung function after $\mathrm{CPB},{ }^{26}$ whereas nebulized exogenous natural surfactant $(30 \mathrm{mg} / \mathrm{kg}$ body weight) appeared to be promising. ${ }^{27}$

Before surfactant therapy after CPB can be safely used in these infants, further systematic studies are needed to define the optimal time point, the type of the surfactant preparation, and the dose to be administered. Only surfactant substitution on a rational data basis 
might be helpful in reducing postoperative morbidity and mortality in these infants and thus needs to be investigated systematically.

The infants with cardiac diseases were operated on at the Department of Cardiac Surgery (B. Reichard), Klinikum Grosshadern, University of Munich, Marchionini Strasse, 81377 Munich, Germany. Perioperative care was delivered at the pediatric cardiology intensive care unit $(\mathrm{H}$. Netz) of the Kinderpoliklinik at the Klinikum Grosshadern, University of Munich, Marchionini Strasse, 81377 Munich, Germany. We thank all the nurses of the pediatric cardiology intensive care unit staff for their continuous support and help with the collection of small-volume lavages.

\section{REFERENCES}

1. Macnaughton PD, Braude S, Hunter DN. Changes in lung function and pulmonary capillary permeability after cardiopulmonary bypass. Crit Care Med 1992;20:1289-94.

2. Tanaka K, Kumon K, Yamamoto F. Respiratory care of pediatric patients requiring prolonged intubation after cardiac surgery. Crit Care Med 1986;14:617-9.

3. Westaby S. Organ dysfunction after cardiopulmonary bypass: a systemic inflammatory reaction initiated by the extracorporeal circuit. Intens Care Med 1987;13:89-95.

4. Tennenberg SD, Clardy CW, Bailey WW. Complement activation and lung permeability during cardiopulmonary bypass. Ann Thorac Surg 1990;50:597-601.

5. Komani H, Haworth SG. The effect of cardiopulmonary bypass on the lung. In: Jonas I, Elliot M, editors. Cardiopulmonary bypass in neonates, infants and young children. Oxford: Butterworth-Heinemann; 1994. p. 242-62.

6. Elliott M, Finn AR. Interaction between neutrophils and endothelium. Ann Thorac Surg 1993;56:1503-8.

7. Moat NE, Shore DF, Evans TW. Organ dysfunction and cardiopulmonary bypass: the role of complement and complement regulatory proteins. Eur J Cardiothoracic Surg 1993;7:563-73.

8. Holm BA. Surfactant inactivation in adult respiratory distress syndrom. In: Robertson B, van Golde L, Batenburg JJ, editors. Pulmonary surfactant: from molecular biology to clinical practice. Amsterdam: Elsevier; 1992. p. 665-84.

9. Walters DD. The role of pulmonary surfactant in transepithelial movement of liquid. In: Robertson B, van Golde L, Batenburg JJ, editors. Pulmonary surfactant: from molecular biology to clinical practice. Amsterdam: Elsevier; 1992. p. 193-213.

10. Lewis JF, Jobe AH. Surfactant and the adult respiratory distress syndrome. Am Rev Respir Dis 1993;147:218-33.

11. Heikinheimo M, Hynynen M, Rautiainen P, Andersson S. Suc- cessful treatment of ARDS with two doses of synthetic surfactant. Chest 1994;105:1263-4.

12. Gregory TJ, Steinberg KP, Spragg R, Gadek JE. Bovine surfactant therapy for patients with acute respiratory distress syndrome. Am J Respir Crit Care Med 1997;155:1309-15.

13. Walmrath D, Günther A, Ghofrani HA, et al. Bronchoscopic surfactant administration in patients with severe adult respiratory distress syndrome and sepsis. Am J Respir Crit Care Med 1996;154: 54-62.

14. Griese M, Dietrich P, Reinhardt D. Pharmocokinetics of bovine surfactant in neonatal respiratory distress syndrome. Am J Respir Crit Care Med 1995;152:1050-4.

15. Gross NJ, Schultz RM. Serine protease requirement for the extracellular metabolism of pulmonary surfactant. Biochim Biophys Acta 1990;1044:222-30.

16. Veldhuizen RW, Inchley K, Hearn SA, Lewis JF, Possmayer JF. Degradation of surfactant-associated protein B (SP-B) during in vitro conversion of large to small surfactant aggregates. Biochem J 1993;141-7.

17. Griese M, Dietrich P, Potz C, Westerburg B, Bals R, Reinhardt D. Surfactant subfractions during nosocomial infection in ventilated preterm human neonates. Am J Respir Crit Care Med 1996;153: 398-403.

18. Griese M, Birrer P, Demirsoy A. Pulmonary surfactant in cystic fibrosis. Eur Respir J 1997;10:1983-8.

19. Motulsky H. Intuitive biostatistics. New York: Oxford University Press, 1995.

20. Shah M, Najafi H, Serry C, Callaghan R, Yang J. Pathophysiological alterations in perfused and non-perfused lungs during cardiopulmonary bypass. Ann Thorac Surg 1970;10:402-8.

21. Marcatili S, Guarino C, Giannattasio A. Alterations of the endoalveolar surfactant after surgery with extracorporeal circulation. Respiration 1990;57:233-8.

22. McGowan FX, Ikegami M, del Nido PJ, Motoyama EK, Kurland G, Davis PJ, et al. Cardiopulmonary bypass significantly reduces surfactant activity in children. J Thorac Cardiovasc Surg 1993; 106:968-77.

23. Nicholas TE, Power JT, Barr HA. The pulmonary consequences of a deep breath. Respir Physiol 1982;49:315-24.

24. Mason RJ. Surfactant secretion. In: Robertson B, van Golde LG, Batenburg JJ, editors. Pulmonary surfactant: from molecular biology to clinical practice. Amsterdam: Elsevier; 1992. p. 295-312.

25. Seeger W, Grube C, Günther A, Schmidt R. Surfactant inhibition by plasma proteins: differential sensitivity of various surfactant preparations. Eur Respir J 1993;6:971-7.

26. Macnaughton PD, Evans TW. The effect of exogenous surfactant therapy on lung function following cardiopulmonary bypass. Chest 1994;105:421-5.

27. DoCampo J, Bertranou EG, De Lorenzi A, Hager AA. Nebulised exogenous natural surfactant after cardiac surgery. Lancet 1994; 343:482. 